OPEN ACCESS

Edited by:

Vincent Pialoux,

Claude Bernard University Lyon 1,

France

Reviewed by:

Charles Christoph Roehr,

Oxford Health NHS Foundation Trust,

United Kingdom

Arjan Te Pas,

Leiden University, Netherlands

*Correspondence:

Hege H. Clemm

hclemm@gmail.com

Specialty section

This article was submitted to

Exercise Physiology,

a section of the journal

Frontiers in Physiology

Received: 12 April 2017

Accepted: 29 June 2017

Published: 13 July 2017

Citation:

Hestnes J, Hoel H, Risa OJ,

Romstøl HO, Røksund O, Frisk B,

Thorsen E, Halvorsen $T$ and

Clemm HH (2017) Ventilatory

Efficiency in Children and Adolescents

Born Extremely Preterm.

Front. Physiol. 8:499.

doi: 10.3389/fphys.2017.00499

\section{Ventilatory Efficiency in Children and Adolescents Born Extremely Preterm}

\author{
Julie Hestnes ${ }^{1}$, Hedda Hoel ${ }^{1}$, Ole J. Risa ${ }^{1}$, Hanna O. Romstøl ${ }^{1}$, Ola Røksund ${ }^{2}$, \\ Bente Frisk ${ }^{2,3}$, Einar Thorsen ${ }^{1}$, Thomas Halvorsen ${ }^{1,4}$ and Hege H. Clemm ${ }^{1,4 *}$ \\ ${ }^{1}$ Department of Clinical Science, University of Bergen, Bergen, Norway, ${ }^{2}$ Department of Occupational Therapy, \\ Physiotherapy and Radiography, Western Norway University of Applied Science, Bergen, Norway, ${ }^{3}$ Department of \\ Physiotherapy, Haukeland University Hospital, Bergen, Norway, ${ }^{4}$ Department of Paediatrics, Haukeland University Hospital, \\ Bergen, Norway
}

Purpose: Children and adolescents born extremely preterm (EP) have lower dynamic lung volumes and gas transfer capacity than subjects born at term. Most studies also report lower aerobic capacity. We hypothesized that ventilatory efficiency was poorer and that breathing patterns differed in EP-born compared to term-born individuals.

Methods: Two area-based cohorts of participants born with gestational age $\leq 28$ weeks or birth weight $\leq 1000 \mathrm{~g}$ in 1982-85 $(n=46)$ and 1991-92 $(n=35)$ were compared with individually matched controls born at term. Mean ages were 18 and 10 years, respectively. The participants performed an incremental treadmill exercise test to peak oxygen uptake with data averaged over $20 \mathrm{~s}$ intervals. For each participant, the relationship between exhaled minute ventilation $\left(\dot{V}_{E}\right)$ and carbon dioxide output $\left(\dot{V} \mathrm{CO}_{2}\right)$ was described by a linear model, and the relationship between tidal volume $\left(V_{T}\right)$ and $\dot{V}_{E}$ by a quadratic model. Multivariate regression analyses were done with curve parameters as dependent variables, and the categories EP vs. term-born, sex, age, height, weight and forced expiratory volume in $1 \mathrm{~s}\left(\mathrm{FEV}_{1}\right)$ as independent variables.

Results: In adjusted analyses, the slope of the $\dot{V}_{E}-\dot{V} C_{2}$ relationship was significantly steeper in the EP than the term-born group, whereas no group difference was observed for the breathing pattern, which was related to $\mathrm{FEV}_{1}$ only.

Conclusion: EP-born participants breathed with higher $\dot{V}_{E}$ for any given $\mathrm{CO}_{2}$ output, indicating lower ventilatory efficiency, possibly contributing to lower aerobic capacity. The breathing patterns did not differ between the EP and term-born groups when adjusted for FEV . $_{\text {. }}$

Keywords: extremely preterm born, exercise, bronchopulmonary dysplasia, respiratory mechanics, pulmonary gas exchange, breathing pattern

\section{INTRODUCTION}

Immense progress during the past 30-40 years in the care of infants born extremely preterm (EP) has markedly increased their prospects of long-term survival. While in the $1970 \mathrm{~s}$ most of these infants died, the situation today is reversed with overall survival rates in the range of $80-$ 90\% (Markestad et al., 2005). When born at this early stage, gas exchange must take place in developmentally fetal lungs still in their canalicular or saccular phase, disturbing growth and development (Jobe and Bancalari, 2001). Studies of EP-born children and adolescents report 
altered acinar structures with fewer and larger alveoli and lower alveolar capillary density, lower dynamic lung volumes, and lower diffusing capacity for carbon monoxide (Cutz and Chiasson, 2008; Satrell et al., 2013; Chang et al., 2016). Most studies on EP-born children and adolescents find lower peak oxygen uptake ( $\mathrm{VO}_{2 \text { peak }}$ ) (Kilbride et al., 2003; Smith et al., 2008; Burns et al., 2009; Welsh et al., 2010; Clemm et al., 2012, 2014, 2015).

Ventilatory mechanical limitations, including limited expansion of the tidal volume $\left(\mathrm{V}_{\mathrm{T}}\right)$, or alveolar gas exchange limitations, may contribute to lower peak exercise capacity. MacLean et al. (2016) reported in a recent study that the slope of the relationship between minute ventilation $\left(\dot{\mathrm{V}}_{\mathrm{E}}\right)$ and carbon dioxide output $\left(\dot{\mathrm{V}} \mathrm{CO}_{2}\right)$ was steeper in children born EP than in a term-born control group. They also found lower peak minute ventilation $\left(\dot{\mathrm{V}}_{\text {Epeak }}\right)$ and peak tidal volume $\left(\mathrm{V}_{\text {Tpeak }}\right)$. The increased slope of the $\dot{\mathrm{V}}_{\mathrm{E}}-\dot{\mathrm{V}}_{2}$ relationship indicate increased dead space ventilation which could be related to increased alveolar dead space, or increased anatomical dead space ventilation due to differences in breathing pattern with a higher breathing frequency $\left(\mathrm{B}_{\mathrm{f}}\right)$. Cardiovascular effects linked to developmental abnormalities or secondary to the changes in pulmonary function may also contribute to a lower $\dot{\mathrm{VO}}_{2 \text { peak }}$. Reduced alveolar capillary capacitance and reduced conductance of the pulmonary circulation could contribute to a reduction in maximal cardiac output and exercise induced pulmonary hypertension (Abman et al., 2017).

Evaluation of exercise capacity by maximal or peak responses cannot provide information about response trajectories from rest to peak. Despite standards for achieving a maximum $\dot{\mathrm{VO}}_{2}$, such end-point criteria are often not met in children (Armstrong and Welsman, 2007). The relationships between $\dot{\mathrm{V}}_{\mathrm{E}}$ and $\dot{\mathrm{VCO}}_{2}$ up to the isocapnic compensation point and between heart rate (HR) and $\dot{\mathrm{VO}}_{2}$ are known to be linear, and we have previously shown that there is a quadratic relationship between $V_{T}$ and $\dot{\mathrm{V}}_{\mathrm{E}}$ (Frisk et al., 2014). When comparing the trajectories by the curve parameters of the responses, the error related to whether a maximum response was achieved or not is reduced.

In the present study, we have compared the $\dot{\mathrm{V}}_{\mathrm{E}}$ vs. $\dot{\mathrm{V}} \mathrm{CO}_{2}$, $\mathrm{HR}$ vs. $\dot{\mathrm{VO}}_{2}$ and $\mathrm{V}_{\mathrm{T}}$ vs. $\dot{\mathrm{V}}_{\mathrm{E}}$ relationships during progressively incremental treadmill exercise in EP and term-born children, and examined possible predictors for the responses including sex, height, weight, age, smoking, leisure-time physical activity, forced vital capacity (FVC) and forced expiratory volume in $1 \mathrm{~s}$ $\left(\mathrm{FEV}_{1}\right)$. We hypothesized that the slope of the $\dot{\mathrm{V}}_{\mathrm{E}}-\dot{\mathrm{V} C O}_{2}$ relationship is higher in $\mathrm{EP}$-born subjects, as demonstrated by MacLean et al. (2016), and that breathing pattern would be different if the increased slope is related to increased anatomical dead space ventilation.

\section{METHODS}

Two population-based birth-cohorts of participants born at gestational age $\leq 28$ weeks or birth weight $\leq 1,000$ gram in 1982 $1985(n=46)$ and 1991-1992 $(n=35)$ were compared with individually matched control groups born at term. Mean ages at the examinations were 18 and 10 years, respectively. These two EP-born cohorts have been extensively followed up for decades, and are hereafter referred to as the 1982-1985 and the 19911992 cohorts. Details as regards their recruitment have been reported in previous communications (Halvorsen et al., 2006; Clemm et al., 2012). Background information was obtained by a questionnaire, including information about level of leisure-time physical activity and smoking. Parental answers were used for the 1991-1992 cohort. FVC and $\mathrm{FEV}_{1}$ were measured with a Vmax22 spirometer (SensorMedics, Yorba Linda, CA, USA) in accordance with European Respiratory Society and American Thoracic Society quality criteria (American Thoracic and American College of Chest, 2003).

An incremental maximal treadmill (ELG 70 Woodway, Weil am Rhein, Germany) exercise test was done in all participants, using the same computerized modified Bruce protocol. Speed and inclination were gradually increased every $90 \mathrm{~s}$. Oxygen uptake $\left(\dot{\mathrm{VO}}_{2}\right)$ and carbon dioxide output $\left(\dot{\mathrm{VCO}}_{2}\right)$, minute ventilation $\left(\dot{\mathrm{V}}_{\mathrm{E}}\right)$, tidal volume $\left(\mathrm{V}_{\mathrm{T}}\right)$ and heart rate $(\mathrm{HR})$ were measured breath by breath by a $V \max 29$ exercise unit (SensorMedics, Yorba Linda, CA, USA). The test was stopped when the participants indicated exhaustion. Anthropometric characteristics, lung function data and peak responses to the exercise test are given in Table 1. The acquisition of background information by questionnaires, and the measurements of lung function and cardiopulmonary exercise capacity have been described in detail in a previous paper analyzing the peak responses to exercise (Clemm et al., 2012). In this present paper, which is based on the same data, we provide extended analyses of the exercise responses, including the progress of submaximal responses.

The Regional Committee for Medical and Health Research Ethics of Western Norway approved the studies (REK-Vest 99.2000). Informed written consent was obtained from all participants or from their parents if they were less than 16 years of age, in accordance with the Declaration of Helsinki. Most of the participants, and all the children born in 1991-1992 (EP-born and term-born), had at least one adult guardian present during testing, usually one of the parents.

\section{Data Processing and Statistics}

Breath by breath measurements of $\dot{\mathrm{V}}_{\mathrm{E}}, \mathrm{V}_{\mathrm{T}}, \dot{\mathrm{VO}_{2}}, \dot{\mathrm{VCO}}_{2}$ and HR were averaged over $20 \mathrm{~s}$ intervals. For each participant the relationship between $\dot{\mathrm{V}}_{\mathrm{E}}$ and $\dot{\mathrm{VCO}}_{2}$ was described by a linear regression model up to the isocapnic compensation point; $\dot{\mathrm{V}}_{\mathrm{E}}$ $=\mathrm{a}+\mathrm{b} \cdot \dot{\mathrm{V}} \mathrm{CO}_{2}$. The relationship between $\mathrm{HR}$ and $\dot{\mathrm{VO}}_{2}$ was also described by a linear model; $\mathrm{HR}=\mathrm{a}+\mathrm{b} \cdot \dot{\mathrm{V}} \mathrm{O}_{2}$. The relationship between $\mathrm{V}_{\mathrm{T}}$ and $\dot{\mathrm{V}}_{\mathrm{E}}$ was described by a quadratic regression model; $\mathrm{V}_{\mathrm{T}}=\mathrm{a}+\mathrm{b} \cdot \dot{\mathrm{V}}_{\mathrm{E}}+\mathrm{c} \cdot \dot{\mathrm{V}}_{\mathrm{E}}^{2}$. The goodness of fit for each response in each participant was evaluated by the $\mathrm{F}$ statistics and the adjusted coefficient of determination $\left(\mathrm{R}^{2}\right) . P$ $<0.05$ was required for inclusion of the participant in further analyses.

Descriptive statistics were used to characterize the study population, including mean and standard deviation (SD), and median and range, as appropriate. Independent samples $t$-tests were used to compare continuous variables. Bivariate and 
TABLE 1 | Participant characteristics and peak responses to progressively incremental exercise test on treadmill.

\begin{tabular}{ccccc}
\multicolumn{2}{c}{ EP-born participants } & & \multicolumn{2}{c}{ Term-born participants } \\
\cline { 1 - 1 } \cline { 5 - 6 } Male & Female & & Male & Female \\
$(n=11)$ & $(n=20)$ & & $(n=12)$ & $(n=22)$
\end{tabular}

\begin{tabular}{|c|c|c|c|c|}
\hline \multicolumn{5}{|c|}{ 1991-1992 birthcohort (age 10 years) } \\
\hline Birth weight (gram) & $968 \pm 196$ & $913 \pm 210$ & $3,565 \pm 292$ & $3,563 \pm 271$ \\
\hline GA at birth (weeks) & $26 \pm 1.3$ & $27 \pm 1.9$ & ** & ** \\
\hline Height (cm) & $138 \pm 6^{*}$ & $140 \pm 9$ & $146 \pm 7$ & $144 \pm 6$ \\
\hline Body mass (kg) & $31 \pm 3^{*}$ & $35 \pm 12$ & $37 \pm 7$ & $39 \pm 7$ \\
\hline FVC (L) & $2.14 \pm 0.31^{*}$ & $2.11 \pm 0.49^{\star}$ & $2.58 \pm 0.23$ & $2.37 \pm 0.29$ \\
\hline $\mathrm{FEV}_{1}(\mathrm{~L})$ & $1.70 \pm 0.21^{*}$ & $1.84 \pm 0.43^{\star}$ & $2.26 \pm 0.23$ & $2.09 \pm 0.29$ \\
\hline $\begin{array}{l}\mathrm{VO}_{2 \text { peak }} \\
\left(\mathrm{L} \cdot \mathrm{min}^{-1}\right)\end{array}$ & $1.45 \pm 0.18^{\star}$ & $1.41 \pm 0.23^{\star}$ & $1.81 \pm 0.11$ & $1.68 \pm 0.24$ \\
\hline $\begin{array}{l}\dot{\mathrm{V}} \mathrm{CO}_{2 \text { peak }} \\
\left(\mathrm{L} \cdot \mathrm{min}^{-1}\right)\end{array}$ & $1.52 \pm 0.23^{\star}$ & $1.52 \pm 0.26^{\star}$ & $1.97 \pm 0.19$ & $1.82 \pm 0.32$ \\
\hline$\dot{\mathrm{V}}_{\text {Epeak }}\left(\mathrm{L} \cdot \mathrm{min}^{-1}\right)$ & $54.9 \pm 9.1^{*}$ & $52.5 \pm 7.6^{\star}$ & $63.3 \pm 8.4$ & $60.7 \pm 13.2$ \\
\hline \multirow[t]{2}{*}{$\mathrm{HR}_{\text {peak }}\left(\min ^{-1}\right)$} & $198 \pm 8$ & $197 \pm 7$ & $203 \pm 7$ & $201 \pm 12$ \\
\hline & $\begin{array}{c}\text { Male } \\
(n=20)\end{array}$ & $\begin{array}{l}\text { Female } \\
(n=17)\end{array}$ & $\begin{array}{c}\text { Male } \\
(n=25)\end{array}$ & $\begin{array}{l}\text { Female } \\
(n=20)\end{array}$ \\
\hline
\end{tabular}

1982-1985 birth-cohort (age 18 years)

\begin{tabular}{|c|c|c|c|c|}
\hline Birth weight (gram) & $1,011 \pm 189$ & $1,029 \pm 201$ & $3,423 \pm 307$ & $3,490 \pm 338$ \\
\hline GA at birth (weeks) & $27 \pm 1.3$ & $27 \pm 1.2$ & $\star \star$ & $\star \star \star$ \\
\hline Height (cm) & $176 \pm 6$ & $164 \pm 4^{*}$ & $177 \pm 6$ & $168 \pm 6$ \\
\hline Body mass (kg) & $68 \pm 15$ & $59 \pm 9$ & $68 \pm 8$ & $67 \pm 15$ \\
\hline FVC (L) & $4.79 \pm 0.80$ & $3.60 \pm 0.46$ & $5.04 \pm 0.75$ & $3.96 \pm 0.62$ \\
\hline $\mathrm{FEV}_{1}(\mathrm{~L})$ & $3.93 \pm 0.59^{\star}$ & * $3.03 \pm 0.42^{\star}$ & $4.47 \pm 0.68$ & $3.52 \pm 0.47$ \\
\hline$\dot{\mathrm{V}} \mathrm{O}_{2 \text { peak }}\left(\mathrm{L} \cdot \mathrm{min}^{-1}\right)$ & $3.50 \pm 0.62$ & $2.41 \pm 0.37$ & $3.79 \pm 0.57$ & $2.68 \pm 0.47$ \\
\hline $\begin{array}{l}\dot{\mathrm{V}} \mathrm{CO}_{2 \text { peak }} \\
\left(\mathrm{L} \cdot \mathrm{min}^{-1}\right)\end{array}$ & $3.80 \pm 0.70$ & $2.63 \pm 0.46^{\star}$ & $4.17 \pm 0.64$ & $3.00 \pm 0.51$ \\
\hline$\dot{\mathrm{V}}_{\text {Epeak }}\left(\mathrm{L} \cdot \mathrm{min}^{-1}\right)$ & $109.8 \pm 23.9$ & $76.1 \pm 16.3$ & $120.2 \pm 25.3$ & $82.9 \pm 9.8$ \\
\hline $\mathrm{HR}_{\text {peak }}\left(\mathrm{min}^{-1}\right)$ & $197 \pm 16$ & $193 \pm 11$ & $198 \pm 9$ & $195 \pm 10$ \\
\hline
\end{tabular}

Mean \pm 1 standard deviation.

*Significantly different from term-born participants of same sex $p<0.05$.

GA gestational age, FVC forced vital capacity, FEV 1 forced expired volume in $1 \mathrm{~s}$, $\dot{V} \mathrm{O}_{2 \text { peak }}$ peak oxygen uptake, $\dot{V} \mathrm{CO}_{2 \text { peak }}$ peak carbon dioxide output, $\dot{V}_{\text {Epeak }}$ peak minute ventilation, $H R_{\text {peak }}$ peak heart rate.

${ }^{\star *} G A$ in term-born participants were $>37$ weeks, exact number not applicable

multivariate linear regression models were constructed, using the curve parameters $\mathrm{a}, \mathrm{b}$, and $\mathrm{c}$ as descriptors of the respective exercise responses (dependent variables), and the categories $\mathrm{EP}$ vs. term-born, height, weight, sex, $\mathrm{FEV}_{1}$ and birth-cohort (reflecting age) as independent and potentially explanatory variables.

The variables included in the multivariate linear regression models were based on results of univariate analyses. The variables EP vs. term-born, sex and birth-cohort were included a priori. FVC was not included in the analyses because of extensive colinearity with $\mathrm{FEV}_{1}$. $\mathrm{FEV}_{1}$ was included as absolute values and not as percentages of predicted or $\mathrm{z}$-scores since sex, age and height were included in all models. Body mass index (BMI) was not included as variable since it includes height and weight. Smoking, which was reported by participants in the elder cohort
TABLE 2 | Curve parameters (a, b, and c) describing the relationships between $\dot{\mathrm{V}}_{\mathrm{E}}$ and $\dot{\mathrm{V}}_{\mathrm{CO}}$, between $\mathrm{HR}$ and $\dot{\mathrm{VO}}_{2}$ and between $\mathrm{V}_{\mathrm{T}}$ and $\dot{\mathrm{V}}_{\mathrm{E}}$.

\begin{tabular}{|c|c|c|c|c|}
\hline & \multicolumn{2}{|c|}{ EP-born participants } & \multicolumn{2}{|c|}{ Term-born participants } \\
\hline & $\begin{array}{c}\text { Male } \\
(n=11)\end{array}$ & $\begin{array}{l}\text { Female } \\
(n=20)\end{array}$ & $\begin{array}{c}\text { Male } \\
(n=12)\end{array}$ & $\begin{array}{l}\text { Female } \\
(n=22)\end{array}$ \\
\hline \multicolumn{5}{|c|}{ 1991-1992 birth-cohort (age 10 years) } \\
\hline \multicolumn{5}{|c|}{$\dot{\mathrm{v}}_{\mathrm{E}}=\mathrm{a}+\mathrm{b} \cdot \dot{\mathrm{v}} \mathrm{CO}_{2}$} \\
\hline $\mathrm{a}$ & $2.4 \pm 1.5$ & $2.2 \pm 1.4$ & $2.3 \pm 1.3$ & $2.1 \pm 1.6$ \\
\hline$b$ & $32.8 \pm 2.1^{\star}$ & $32.1 \pm 2.8$ & $29.5 \pm 2.2$ & $30.7 \pm 3.4$ \\
\hline \multicolumn{5}{|c|}{$\mathrm{HR}=\mathrm{a}+\mathrm{b} \cdot \dot{\mathrm{V}} \mathrm{O}_{2}$} \\
\hline a & $75 \pm 12$ & $70 \pm 10$ & $74 \pm 13$ & $77 \pm 16$ \\
\hline $\mathrm{b}$ & $93 \pm 10^{\star}$ & $100 \pm 15^{\star}$ & $79 \pm 9$ & $82 \pm 18$ \\
\hline \multicolumn{5}{|c|}{$\mathbf{v}_{\mathrm{T}}=\mathbf{a}+\mathbf{b} \cdot \dot{\mathbf{V}}_{\mathrm{E}}+\mathbf{c} \cdot \dot{\mathbf{v}}_{\mathrm{E}}^{2}$} \\
\hline a & $0.17 \pm 0.09$ & $0.17 \pm 0.10$ & $0.14 \pm 0.10$ & $0.22 \pm 0.20$ \\
\hline$b\left(\cdot 10^{-2}\right)$ & $2.4 \pm 1.0$ & $2.6 \pm 0.6$ & $3.0 \pm 0.9$ & $2.8 \pm 0.8$ \\
\hline \multirow[t]{2}{*}{$c\left(\cdot 10^{-4}\right)$} & $-2.0 \pm 1.6$ & $-1.9 \pm 1.0$ & $-2.1 \pm 1.1$ & $-2.1 \pm 1.4$ \\
\hline & $\begin{array}{c}\text { Male } \\
(n=20)\end{array}$ & $\begin{array}{l}\text { Female } \\
(n=17)\end{array}$ & $\begin{array}{c}\text { Male } \\
(n=25)\end{array}$ & $\begin{array}{l}\text { Female } \\
(n=20)\end{array}$ \\
\hline \multicolumn{5}{|c|}{ 1982-1985 birth-cohort (age 18 years) } \\
\hline \multicolumn{5}{|c|}{$\dot{\mathrm{v}}_{\mathrm{E}}=\mathrm{a}+\mathrm{b} \cdot \dot{\mathrm{v}} \mathrm{CO}_{2}$} \\
\hline a & $2.7 \pm 1.7$ & $3.3 \pm 1.9$ & $2.3 \pm 2.0$ & $4.2 \pm 1.6$ \\
\hline$b$ & $25.4 \pm 2.0$ & $26.2 \pm 3.9$ & $25.1 \pm 2.8$ & $25.2 \pm 3.1$ \\
\hline \multicolumn{5}{|c|}{$\mathrm{HR}=\mathrm{a}+\mathrm{b} \cdot \dot{\mathrm{V}} \mathrm{O}_{2}$} \\
\hline a & $65 \pm 11$ & $68 \pm 13$ & $68 \pm 12$ & $75 \pm 14$ \\
\hline$b$ & $40 \pm 8$ & $57 \pm 9$ & $39 \pm 5$ & $51 \pm 12$ \\
\hline \multicolumn{5}{|c|}{$\mathbf{V}_{\mathrm{T}}=\mathbf{a}+\mathbf{b} \cdot \dot{\mathbf{v}}_{\mathrm{E}}+\mathbf{c} \cdot \dot{\mathbf{v}}_{\mathrm{E}}^{2}$} \\
\hline a & $0.24 \pm 0.20$ & $0.09 \pm 0.17$ & $0.29 \pm 0.16$ & $0.17 \pm 0.16$ \\
\hline$b\left(\cdot 10^{-2}\right)$ & $3.7 \pm 0.9$ & $4.5 \pm 1.2$ & $3.8 \pm 0.9$ & $4.0 \pm 1.1$ \\
\hline$c\left(\cdot 10^{-4}\right)$ & $-1.8 \pm 0.8$ & $-3.5 \pm 1.9^{\star}$ & $-1.7 \pm 1.0$ & $-2.4 \pm 1.1$ \\
\hline
\end{tabular}

Mean \pm 1 standard deviation.

* significantly different from controls of same sex $p<0.05$

$\dot{V} \mathrm{~V}_{2}$ oxygen uptake, $\dot{V} \mathrm{CO}_{2}$ carbon dioxide output, $\dot{V}_{E}$ minute ventilation, HR heart rate.

only, and level of habitual physical activity were not related to the dependent variables in univariate analysis.

Estimated regression coefficients are presented with 95\% confidence intervals (CI). The significance level was set at 0.05. The data analyses were performed using IBM SPSS Statistics 21 (SPSS Inc., Chicago, IL).

\section{RESULTS}

In a previous study we have demonstrated that the EP-born participants had lower height, body mass, FVC and $\mathrm{FEV}_{1}$ than the term-born controls, and their peak responses to exercise were also lower (Clemm et al., 2012).

The relationships $\dot{\mathrm{V}}_{\mathrm{E}}$ vs. $\dot{\mathrm{V} C O}_{2}$ and $\mathrm{HR}$ vs. $\dot{\mathrm{VO}}_{2}$ could be satisfactorily described by the linear models in all participants. Median $R^{2}$ was 0.98 (range 0.96-0.99) and 0.90 (range 0.710.99), respectively. The relationship between $V_{T}$ vs. $\dot{V}_{E}$ was satisfactorily described by a quadratic model in all but two participants. Median $R^{2}$ was 0.95 (range $0.45-0.99$ ). The curve 
TABLE 3 | Multiple regression analyses for the curve parameters describing the relationship between $\dot{\mathrm{V}}_{\mathrm{E}}$ and $\dot{\mathrm{V}}_{\mathrm{CO}}, \dot{\mathrm{V}}_{\mathrm{E}}=\mathrm{a}+\mathrm{b} \cdot \dot{\mathrm{V}} \mathrm{CO}_{2}$

\begin{tabular}{|c|c|c|c|c|c|c|}
\hline & \multicolumn{2}{|c|}{ Bivariate } & \multicolumn{4}{|c|}{ Multivariate } \\
\hline & B & $\mathbf{p}$ & B & Adjusted B & $95 \% \mathrm{Cl}$ & $\mathbf{p}$ \\
\hline \multicolumn{7}{|c|}{ Curve Parameter a } \\
\hline Case/Control & 0.13 & 0.802 & 0.37 & 0.11 & $-0.22,0.97$ & 0.213 \\
\hline Sex & 0.44 & 0.130 & 0.30 & 0.09 & $-0.33,0.94$ & 0.348 \\
\hline $\mathrm{FEV}_{1}$ & 0.12 & 0.387 & -1.17 & -0.73 & $-1.89,-0.45$ & 0.002 \\
\hline Height & 0.02 & 0.026 & 0.05 & 0.51 & $-0.003,0.11$ & 0.063 \\
\hline Body mass & 0.02 & 0.039 & 0.001 & 0.01 & $-0.03,0.03$ & 0.941 \\
\hline Cohort & -0.87 & 0.003 & -1.42 & -0.40 & $-2.68,-0.16$ & 0.028 \\
\hline \multicolumn{7}{|c|}{ Curve Parameter b } \\
\hline Case/Control & -1.39 & 0.043 & -1.12 & -0.14 & $-2.13,-0.12$ & 0.029 \\
\hline Sex & 1.49 & 0.029 & 0.15 & 0.02 & $-0.93,1.23$ & 0.782 \\
\hline $\mathrm{FEV}_{1}$ & -2.42 & 0.000 & 1.06 & 0.28 & $-0.17,2.29$ & 0.090 \\
\hline Height & -0.18 & 0.000 & -0.13 & -0.51 & $-0.23,-0.03$ & 0.011 \\
\hline Body mass & -0.15 & 0.000 & -0.03 & -0.14 & $-0.09,0.02$ & 0.268 \\
\hline Cohort & 5.85 & 0.000 & 3.04 & 0.37 & $0.90,5.18$ & 0.006 \\
\hline
\end{tabular}

FEV forced expired volume in $1 \mathrm{~s}, \dot{\mathrm{V} C \mathrm{CO}_{2}}$ carbon dioxide output.

TABLE 4 | Multiple regression analyses for the curve parameters describing the relationship between $\mathrm{HR}$ and $\dot{\mathrm{VO}}_{2}, \mathrm{HR}=\mathrm{a}+\mathrm{b} \cdot \dot{\mathrm{V}}_{2}$.

\begin{tabular}{|c|c|c|c|c|c|c|}
\hline & \multicolumn{2}{|c|}{ Bivariate } & \multirow[b]{2}{*}{ B } & \multicolumn{3}{|c|}{ Multivariate } \\
\hline & B & $\mathbf{p}$ & & Adjusted B & $95 \% \mathrm{Cl}$ & $\mathbf{p}$ \\
\hline \multicolumn{7}{|c|}{ Curve Parameter a } \\
\hline Case/Control & 4.23 & 0.051 & 4.87 & 0.19 & $0.37,9.37$ & 0.034 \\
\hline Sex & 3.72 & 0.087 & 1.68 & 0.07 & $-3.18,6.53$ & 0.495 \\
\hline $\mathrm{FEV}_{1}$ & -2.08 & 0.027 & 1.48 & 0.13 & $-4.01,6.98$ & 0.597 \\
\hline Height & -0.18 & 0.005 & -0.35 & -0.45 & $-0.78,0.06$ & 0.113 \\
\hline Body mass & -0.09 & 0.027 & 0.03 & 0.04 & $-0.21,0.28$ & 0.803 \\
\hline Cohort & 4.17 & 0.049 & -1.82 & -0.07 & $-11.41,7.76$ & 0.708 \\
\hline \multicolumn{7}{|c|}{ Curve Parameter b } \\
\hline Case/Control & -10.5 & 0.013 & -6.24 & -0.12 & $-10.01,-2.47$ & 0.001 \\
\hline Sex & 18.2 & 0.000 & 6.88 & 0.14 & $2.81,10.94$ & 0.001 \\
\hline $\mathrm{FEV}_{1}$ & -19.7 & 0.000 & -0.12 & -0.01 & $-4.73,4.49$ & 0.959 \\
\hline Height & -1.4 & 0.000 & -0.42 & -0.28 & $-0.79,-0.06$ & 0.024 \\
\hline Body mass & -1.2 & 0.000 & -0.38 & -0.28 & $-0.59,-0.18$ & 0.000 \\
\hline Cohort & 43.0 & 0.000 & 17.23 & 0.34 & $9.2,25.3$ & 0.000 \\
\hline
\end{tabular}

FEV $V_{1}$ forced expired volume in $1 \mathrm{~s}$, HR heart rate, $\dot{V}_{2}$ oxygen uptake.

parameters for the relationships are given in Table 2, split by birth-cohort and sex.

The intercept of the linear relationship $\dot{\mathrm{V}}_{\mathrm{E}}$ vs. $\dot{\mathrm{VCO}}_{2}$ was significantly related to $\mathrm{FEV}_{1}$ and cohort, but not to the other independent variables included in the model. Participants in the 1991-1992 birth-cohort and participants with a higher $\mathrm{FEV}_{1}$ had a lower intercept (Table 3). The slope was higher in the 19911992 birth-cohort, and higher with increasing height, and also higher in the EP than the term-born groups.
TABLE 5 | Multiple regression analyses for the curve parameters describing the relationship between $V_{T}$ and $\dot{V}_{E}, V_{T}=a+b \cdot \dot{V}_{E}+c \cdot \dot{V}_{E}^{2}$

\begin{tabular}{|c|c|c|c|c|c|c|}
\hline & \multicolumn{2}{|c|}{ Bivariate } & \multirow[b]{2}{*}{ B } & \multicolumn{3}{|c|}{ Multivariate } \\
\hline & B & $\mathbf{p}$ & & Adjusted B & $95 \% \mathrm{Cl}$ & $\mathbf{p}$ \\
\hline \multicolumn{7}{|c|}{ Curve Parameter a } \\
\hline Case/Control & 0.05 & 0.108 & 0.02 & 0.05 & $-0.04,0.08$ & 0.541 \\
\hline Sex & -0.06 & 0.025 & -0.02 & 0.03 & $-0.09,0.04$ & 0.464 \\
\hline $\mathrm{FEV}_{1}$ & 0.03 & 0.010 & 0.05 & 0.34 & $-0.02,0.12$ & 0.157 \\
\hline Height & 0.01 & 0.041 & 0.002 & 0.16 & $-0.01,0.01$ & 0.570 \\
\hline Body mass & 0.01 & 0.150 & -0.001 & -0.09 & $-0.01,0.01$ & 0.594 \\
\hline Cohort & -0.03 & 0.381 & 0.097 & 0.29 & $-0.03,0.22$ & 0.124 \\
\hline
\end{tabular}

\section{Curve Parameter b $\left(\cdot 10^{-2}\right)$}

$\begin{array}{lcccrrr}\text { Case/Control } & 0.1 & 0.747 & 0.1 & 2.9 & -0.3,0.4 & 0.701 \\ \text { Sex } & 1.0 & 0.915 & 0.2 & 8.6 & -0.2,0.6 & 0.296 \\ \text { FEV }_{1} & 4.0 & 0.000 & -0.1 & -12.3 & -0.6,0.3 & 0.554 \\ \text { Height } & 0.1 & 0.000 & 0.01 & 6.0 & -0.1,0.1 & 0.809 \\ \text { Body mass } & 0.03 & 0.000 & 0.03 & 4.9 & -0.1,0.1 & 0.750 \\ \text { Cohort } & -1.3 & 0.000 & -1.3 & -57.2 & -2.0,-0.6 & 0.001\end{array}$

\section{Curve Parameter c $\left(\cdot 10^{-4}\right)$}

$\begin{array}{lcccccc}\text { Case/Control } & 0.25 & 0.265 & -0.04 & -160 & -4.9,4.1 & 0.849 \\ \text { Sex } & -0.6 & 0.006 & -0.30 & -119 & -0.8,1.7 & 0.197 \\ \text { FEV }_{1} & 0.15 & 0.135 & 0.64 & 524 & 0.1,1.2 & 0.025 \\ \text { Height } & 0.04 & 0.570 & 0.02 & 280 & -0.4,0.5 & 0.920 \\ \text { Body mass } & 0.02 & 0.782 & 0.001 & 40 & -0.2,0.2 & 0.983 \\ \text { Cohort } & 0.24 & 0.282 & 1.0 & 566 & 0.6,2.5 & 0.020\end{array}$

$F E V_{1}$ forced expired volume in $1 s, V_{T}$ tidal volume, $\dot{V}_{E}$ minute ventilation.

The intercept of the linear relationship $\mathrm{HR}$ vs. $\dot{\mathrm{VO}}_{2}$ was significantly related to sex, height, body mass and birth-cohort, but not to EP vs. term-born (Table 4). The slope was related to sex, height, body mass and cohort, and significantly higher in the EP-born group. Birth-cohort (1982-1985 vs. 1991-1992) reflected not only the age differences, but also the fact that participants in the 1991-1992 cohort were pre-pubertal and participants in the 1982-1985 cohort post-pubertal.

The curve parameters of the quadratic relationship between $\mathrm{V}_{\mathrm{T}}$ and $\dot{\mathrm{V}}_{\mathrm{E}}$ were all different between the cohorts, and the curvature (parameter c) was related to $\mathrm{FEV}_{1}$ (Table 5). Participants in the 1991-1992 cohort and participants with a lower $\mathrm{FEV}_{1}$ had a lower maximal $\mathrm{V}_{\mathrm{T}}$ at a lower $\dot{\mathrm{V}}_{\mathrm{E}}$. At a given $\dot{\mathrm{V}}_{\mathrm{E}}$ there was no difference in $\mathrm{V}_{\mathrm{T}}$ between the EP and term-born groups when adjusted for $\mathrm{FEV}_{1}$.

The relationships are demonstrated in Figure 1.

\section{DISCUSSION}

This is the first study to show that cardiopulmonary exercise responses can be satisfactorily described in the vast majority of preterm born children and young adults by using mathematical regression models previously applied and tested only in adult patients with COPD. The EP-born participants differed from 


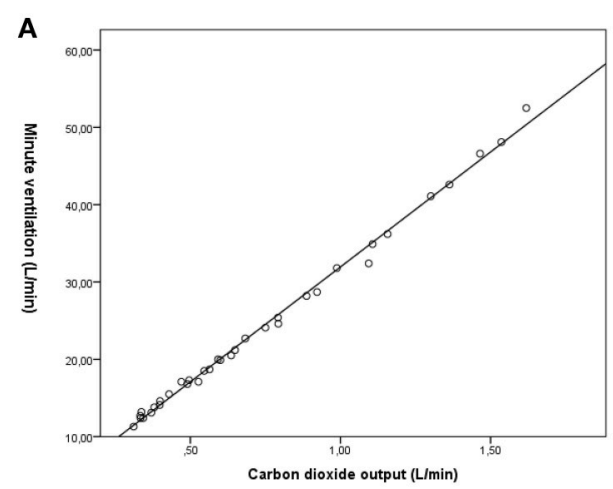

B

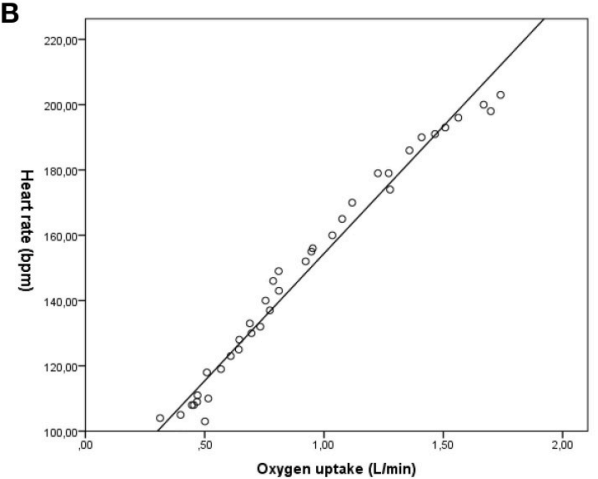

C

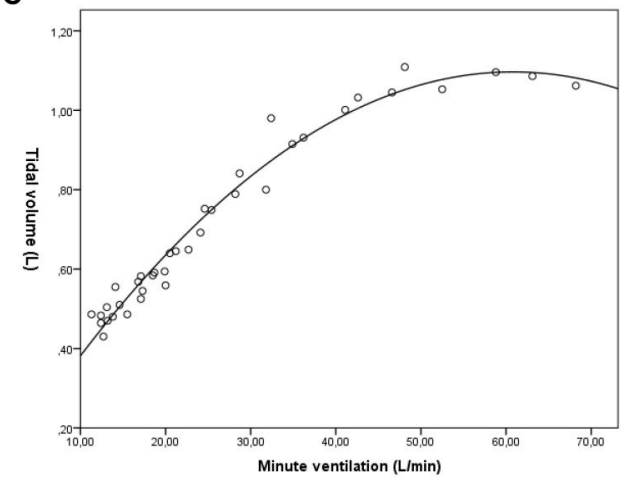

D

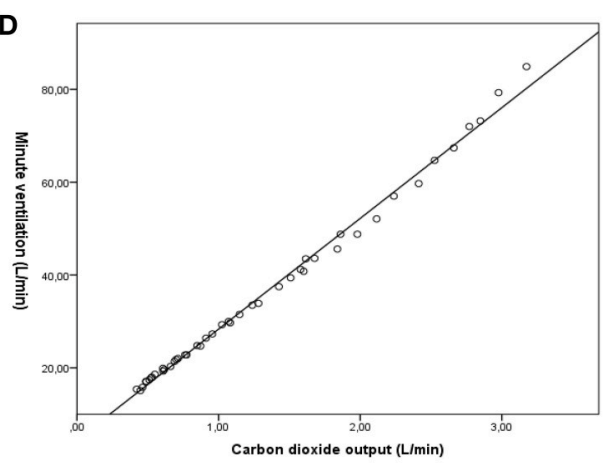

E

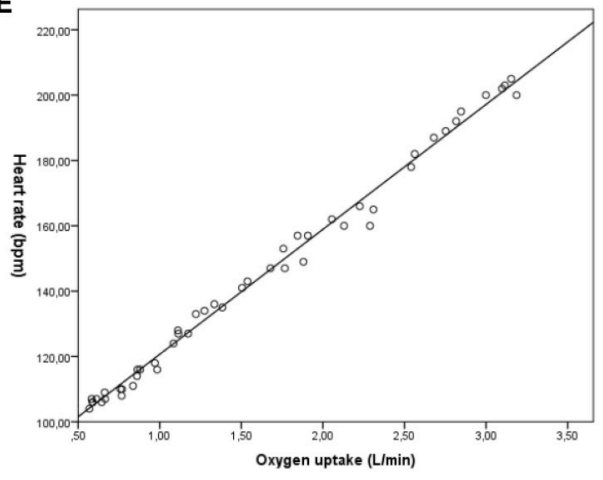

$\mathbf{F}$

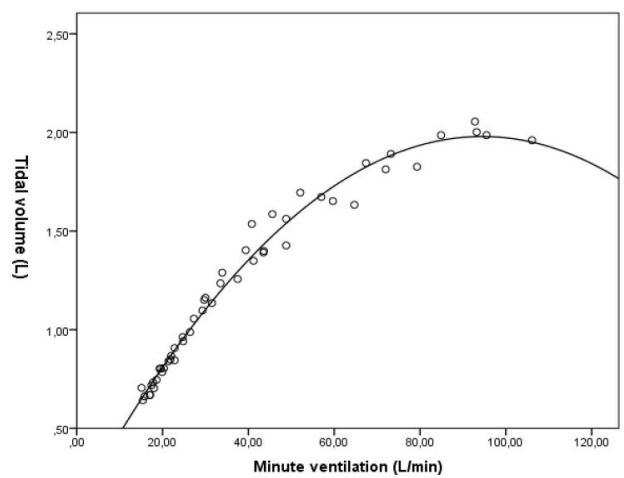

FIGURE 1 | The relationships between ventilation and carbon dioxide output, heart rate and oxygen uptake, and tidal volume and ventilation. Two randomly selected participants, one from the 1991-1992 cohort at 10 years of age (left column A-C), and one from the 1982-1985 cohort at 18 years of age (right column $\mathbf{D - F}$ ).

the term-born controls in that the slopes for the relationships between $\dot{\mathrm{VE}}$ vs. $\dot{\mathrm{V} C O}$, and $\mathrm{HR}$ vs. $\dot{\mathrm{VO}}_{2}$, were significantly higher; i.e., $\dot{V} E$ was significantly higher for a given $\mathrm{CO}_{2}$ output, and $\mathrm{HR}$ was higher for a given $\mathrm{O}_{2}$ uptake after adjusting for anthropometric characteristics and $\mathrm{FEV}_{1}$. The breathing patterns were related to $\mathrm{FEV}_{1}$ irrespective of $\mathrm{EP}$ or term-born group status.

The higher slope of the $\dot{\mathrm{V}}_{\mathrm{E}}-\dot{\mathrm{V}} \mathrm{CO}_{2}$ relationship for EP-born indicates higher dead space ventilation. This could be related to increased ventilation of the anatomical dead space because of shallower breathing at higher breathing frequencies (Chang et al., 2016). There were no differences in the relationship between $\mathrm{V}_{\mathrm{T}}$ and $\dot{\mathrm{V}}_{\mathrm{E}}$ between the groups after adjusting for $\mathrm{FEV}_{1}$. Since $\dot{\mathrm{V}}_{\mathrm{E}}=\mathrm{V}_{\mathrm{T}} \cdot \mathrm{B}_{\mathrm{f}}$, participants born extremely preterm will have the same $\mathrm{B}_{\mathrm{f}}$ at a given $\dot{\mathrm{V}}_{\mathrm{E}}$, indicating that ventilation of the anatomical dead space is not different after adjusting for $\mathrm{FEV}_{1}$. Thus, differences in breathing pattern cannot explain the higher slope of the $\dot{\mathrm{V}}_{\mathrm{E}}-\dot{\mathrm{V}} \mathrm{CO}_{2}$ relationship, and differences in alveolar dead space ventilation are more likely. The higher slope means a higher ventilatory equivalent for $\mathrm{CO}_{2}$. When the ventilatory equivalent, which is $\dot{\mathrm{V}}_{\mathrm{E}} / \mathrm{V}_{\mathrm{CO}}$, is related to $\dot{\mathrm{V}} \mathrm{CO}_{2}$ it is just a mathematical transformation of the $\dot{\mathrm{V}}_{\mathrm{E}}-\dot{\mathrm{V}}_{2}$ relationship. A higher alveolar dead space in participants born extremely preterm is consistent with a lower diffusion capacity for carbon monoxide. The infants are born with developmentally fetal lungs, and further development of the lung is disturbed resulting in fewer and larger alveoli, and lower alveolar capillary density. There are few autopsy studies from EP-born individuals after 
infancy (Cutz and Chiasson, 2008), but those that we have from infants dying from severe bronchopulmonary dysplasia (BPD) suggest dysplastic acini with fewer and larger alveoli, and lower alveolar capillary density (De Paepe et al., 2006; Cutz and Chiasson, 2008), possibly pathways to later increased alveolar deadspace ventilation. Imaging studies generally agree that EP birth is associated with long-standing and structural injuries, although the findings have varied (Aukland et al., 2006; Wong et al., 2008; Simpson et al., 2017). Recent studies suggest that although injured in their neonatal period, alveolar growth might continue in these children, at least until school age, so these issues are not solved (Weibel, 2008; Narayanan et al., 2013).

BPD represents a categorization of preterm born individuals, based on prolonged requirements for supplemental oxygen (Jobe and Bancalari, 2001) and primarily (but not exclusively) reflects the severity of neonatal respiratory disease. As regards EP-born participants of the present study, major progress in neonatal intensive care had occurred between the two periods in which they were born (1982-1985 and 1991-1992). The possibility to provide exogenous surfactant stands out as particularly important. Surfactant treatment was unavailable in the early 1980 s, contrasting the $1990 \mathrm{~s}$ were surfactant was in regular use; in our unit in the form of Exosurf ${ }^{\mathbb{R}}$ as prescribed by the Osiris trial (Group, 1992). Clinically, these changes led to a less severe form of neonatal BPD, often labeled "new BPD” contrasting the "old" and more severe version of the disease (Coalson, 2006) However, despite better treatments the long-term lung function outcomes of the 1982-1985 and 1991-1992 cohorts did not differ significantly, as presented and discussed in detail in a previous communication (Halvorsen et al., 2006). In line with all long-term follow-up studies of preterm born individuals, this present study is faced with the obvious limitation that data cannot necessarily be extrapolated to survivors of today's situation, where more immature individuals exposed to more advanced therapies survive and grow up. Differences in neonatal practices, both between time eras and geographical areas, impact survival rates and long-term outcomes in ways that can be difficult to predict (Kotecha et al., 2013; Vollsaeter et al., 2015). This scenario calls for continuing "surveillance processes" in the form of comprehensive follow-up studies that can provide valuable feedback to involved health care providers. BPD has in many studies been linked to lower $\mathrm{FEV}_{1}$, diffusing capacity and peak aerobic exercise capacity (Bader et al., 1987; Santuz et al., 1995; Jacob et al., 1997; Kriemler et al., 2005; Joshi et al., 2013) in childhood and adolescence. In our previous published study (Clemm et al., 2012), we did not find that BPD was related to $\dot{\mathrm{VO}}$ 2peak .

Reduced pulmonary capillary capacitance and pulmonary vascular conductance may have secondary cardiovascular effects with a lower maximal cardiac output and oxygen pulse ( $\dot{\mathrm{VO}}_{2} / \mathrm{HR}$ ). The slope of the relationship between $\mathrm{HR}$ and $\dot{\mathrm{VO}}_{2}$ was higher in EP-born group, but the intercept was not different. When extrapolating to the maximal $\mathrm{HR}$, which was the same, $\dot{\mathrm{VO}}_{2 \max }$ will be lower. $\dot{\mathrm{V}} \mathrm{O}_{2 \text { peak }}$ was numerically lower in the $\mathrm{EP}$-born participants, but was not significantly different from the term-born control group when adjusted for weight. However, the significantly steeper $\mathrm{HR}-\dot{\mathrm{VO}}_{2}$ slope supports the numerical data, particularly as other studies have demonstrated a lower $\dot{\mathrm{VO}}_{2 \text { peak }}$ in EP-born children (Kilbride et al., 2003; Smith et al., 2008; Burns et al., 2009; Welsh et al., 2010; Clemm et al., 2012, 2014, 2015).

The oxygen pulse $\left(\dot{\mathrm{VO}}_{2} / \mathrm{HR}\right)$ is just a mathematical transformation of the $\mathrm{HR}-\dot{\mathrm{V}} \mathrm{O}_{2}$ relationship, and when related to $\dot{\mathrm{VO}}_{2}$ it is a hyperbola with the asymptote, or the maximal $\dot{\mathrm{VO}}_{2} / \mathrm{HR}$ being equal to the slope of the linear relationship. When oxygen extraction or arteriovenous difference in oxygen content is the same, $\dot{\mathrm{VO}}_{2} / \mathrm{HR}$ is related to stroke volume. So, if oxygen extraction is the same, participants born extremely preterm have lower maximal stroke volume. Aerobic capacity is related to habitual physical activity and exercise training, and can also be related to stroke volume. It was shown in the previously published study that the EP-born participants were less active than the term-born, and that the level of physical activity was related to $\dot{\mathrm{VO}}_{2 \text { peak }}(\mathrm{Clemm}$ et al., 2012). However, the relationships between level of physical activity and $\dot{\mathrm{VO}}_{2 \text { peak }}$ were not different in the two groups.

With respect to the relationship between $\mathrm{HR}$ and $\mathrm{VO}_{2}$ a lower slope is expected in physically fit participants. Only the slope, and not the intercept, was lower in the term-born group, which means that resting heart rate is lower. The intercept is the extreme end of the relationship and has no physiological meaning. Whether differences in physical fitness or cardiovascular effects secondary to the differences in lung function contribute to a lower $\mathrm{VO}_{2 \text { peak }}$ remains unanswered. However, if $\mathrm{EP}-$ born participants have exercise induced pulmonary hypertension as indicated in a recent study (Abman et al., 2017), a higher slope of the $\mathrm{HR}-\dot{\mathrm{VO}}_{2}$ relationship would be expected, and a higher slope of the $\mathrm{V}_{\mathrm{E}}-\dot{\mathrm{V}} \mathrm{CO}_{2}$ is a characteristic of pulmonary hypertension (Schwaiblmair et al., 2012). The functional significance is modest only and the alveolar to arterial difference in oxygen pressure appear not to be widened (Duke et al., 2014), indicating that ventilatory capacity is not limiting exercise.

In the majority of the children and adolescents the responses could be described by mathematical models. We have previously shown that this can be done in healthy physically fit young adults (Kjelkenes and Thorsen, 2010) and in patients having chronic obstructive lung disease (Frisk et al., 2014). In healthy participants there were no differences in the curve parameters between maximal and submaximal exercise tests with the same protocol done on separate days within 1 week (Kjelkenes and Thorsen, 2010). Any criteria for having achieved the maximum oxygen uptake are less important when the trajectories of the responses are compared. However, that is not to say that the maximum or peak responses achieved are not important by themselves.

We conclude that the differences observed in ventilatory efficiency between EP and term-born groups were due to a higher alveolar deadspace, and that breathing patterns were similar in the EP and term-born groups after adjusting for lung and body size. The responses to exercise could be satisfactorily described by the mathematical models on an individual basis, providing important physiological information beyond what can be extracted from peak responses. 


\section{AUTHOR CONTRIBUTIONS}

There are two first authors; $\mathrm{JH}$ and $\mathrm{HH}$; they have contributed equally to the study and writing this manuscript. All authors have contributed substantial to the concept and design of the study. All authors have revised the manuscript critically for important intellectual content and final approved the version to be published. There is an agreement among the authors for all aspect of the work in

\section{REFERENCES}

Abman, S. H., Collaco, J. M., Shepherd, E. G., Keszler, M., CuevasGuaman, M., Welty, S. E., et al. (2017). Interdisciplinary care of children with severe Bronchopulmonary Dysplasia. J. Pediatr. 181, 12-28.e1. doi: $10.1016 /$ j.jpeds.2016.10.082

American Thoracic, S., and American College of Chest, P. (2003). ATS/ACCP Statement on cardiopulmonary exercise testing. Am. J. Respir. Crit. Care Med. 167, 211-277. doi: 10.1164/rccm.167.2.211

Armstrong, N., and Welsman, J. R. (2007). Aerobic fitness: what are we measuring? Med. Sport Sci. 50, 5-25. doi: 10.1159/000101073

Aukland, S. M., Halvorsen, T., Fosse, K. R., Daltveit, A. K., and Rosendahl, K. (2006). High-resolution CT of the chest in children and young adults who were born prematurely: findings in a population-based study. AJR Am. J. Roentgenol. 187, 1012-1018. doi: 10.2214/AJR.05.0383

Bader, D., Ramos, A. D., Lew, C. D., Platzker, A. C., Stabile, M. W., and Keens, T. G. (1987). Childhood sequelae of infant lung disease: exercise and pulmonary function abnormalities after bronchopulmonary dysplasia. J. Pediatr. 110, 693-699. doi: 10.1016/S0022-3476(87)80004-5

Burns, Y. R., Danks, M., O’Callaghan, M. J., Gray, P. H., Cooper, D., Poulsen, L., et al. (2009). Motor coordination difficulties and physical fitness of extremely-low-birthweight children. Dev. Med. Child Neurol. 51, 136-142. doi: 10.1111/j.1469-8749.2008.03118.x

Chang, D. V., Assaf, S. J., Tiller, C. J., Kisling, J. A., and Tepper, R. S. (2016). Membrane and capillary components of lung diffusion in infants with Bronchopulmonary Dysplasia. Am. J. Respir. Crit. Care Med. 193, 767-771. doi: 10.1164/rccm.201506-1219OC

Clemm, H. H., Vollsaeter, M., Roksund, O. D., Eide, G. E., Markestad, T., and Halvorsen, T. (2014). Exercise capacity after extremely preterm birth: development from adolescence to adulthood. Ann. Am. Thorac. Soc. 11, 537-545. doi: 10.1513/AnnalsATS.201309-311OC

Clemm, H. H., Vollsaeter, M., Roksund, O. D., Markestad, T., and Halvorsen, T. (2015). Adolescents who were born extremely preterm demonstrate modest decreases in exercise capacity. Acta Paediatr. 104, 1174-1181. doi: 10.1111/apa.13080

Clemm, H., Roksund, O., Thorsen, E., Eide, G. E., Markestad, T., and Halvorsen, T. (2012). Aerobic capacity and exercise performance in young people born extremely preterm. Pediatrics 129, e97-e105. doi: 10.1542/peds.2011-0326

Coalson, J. J. (2006). Pathology of bronchopulmonary dysplasia. Semin. Perinatol. 30, 179-184. doi: 10.1053/j.semperi.2006.05.004

Cutz, E., and Chiasson, D. (2008). Chronic lung disease after premature birth. New Eng. J. Med. 358, 743-745. doi: 10.1056/NEJMc073362

De Paepe, M. E., Mao, Q., Powell, J., Rubin, S. E., DeKoninck, P., Appel, N., et al. (2006). Growth of pulmonary microvasculature in ventilated preterm infants. Am. J. Respir. Crit. Care Med. 173, 204-211. doi: 10.1164/rccm.200506-927OC

Duke, J. W., Elliott, J. E., Laurie, S. S., Beasley, K. M., Mangum, T. S., Hawn, J. A., et al. (2014). Pulmonary gas exchange efficiency during exercise breathing normoxic and hypoxic gas in adults born very preterm with low diffusion capacity. J. Appl. Physiol. 117, 473-481. doi: 10.1152/japplphysiol.00307.2014

Frisk, B., Espehaug, B., Hardie, J. A., Strand, L. I., Moe-Nilssen, R., Eagan, T. M., et al. (2014). Airway obstruction, dynamic hyperinflation, and breathing pattern during incremental exercise in COPD patients. Physiol. Rep. 2:e00222. doi: $10.1002 /$ phy 2.222 this study, ensuring that questions related to the accuracy and any part of the work are appropriately investigated and resolved.

\section{FUNDING}

The funding institution for this research was Western Norway Regional Health Authority, Haukeland University Hospital, Norway.

Group, T. O. C. (1992). Early versus delayed neonatal administration of a synthetic surfactant-the judgment of OSIRIS (open study of infants at high risk of or with respiratory insufficiency-the role of surfactant). Lancet 340, 1363-1369. doi: 10.1016/0140-6736(92)92557-V

Halvorsen, T., Skadberg, B. T., Eide, G. E., Roksund, O. D., and Markestad, T. (2006). Better care of immature infants; has it influenced long-term pulmonary outcome? Acta Paediatr. 95, 547-554. doi: 10.1080/08035250500477529

Jacob, S. V., Lands, L. C., Coates, A. L., Davis, G. M., MacNeish, C. F., Hornby, L., et al. (1997). Exercise ability in survivors of severe bronchopulmonary dysplasia. Am. J. Respir. Crit. Care Med. 155, 1925-1929. doi: 10.1164/ajrccm.155.6.9196097

Jobe, A. H., and Bancalari, E. (2001). Bronchopulmonary dysplasia. Am. J. Respir. Crit. Care Med. 163, 1723-1729. doi: 10.1164/ajrccm.163.7.2011060

Joshi, S., Powell, T., Watkins, W. J., Drayton, M., Williams, E. M., and Kotecha, S. (2013). Exercise-induced bronchoconstriction in school-aged children who had chronic lung disease in infancy. J. Pediatr. 162, 813-818e1. doi: 10.1016/j.jpeds.2012.09.040

Kilbride, H. W., Gelatt, M. C., and Sabath, R. J. (2003). Pulmonary function and exercise capacity for ELBW survivors in preadolescence: effect of neonatal chronic lung disease. J. Pediatr. 143, 488-493. doi: 10.1067/S0022-3476(03)00413-X

Kjelkenes, I., and Thorsen, E. (2010). Anticipating maximal or submaximal exercise: no differences in cardiopulmonary responses. Clin. Physiol. Funct. Imaging. 30, 333-337. doi: 10.1111/j.1475-097X.2010.00948.x

Kotecha, S. J., Edwards, M. O., Watkins, W. J., Henderson, A. J., Paranjothy, S., Dunstan, F. D., et al. (2013). Effect of preterm birth on later FEV1: a systematic review and meta-analysis. Thorax 68, 760-766. doi: 10.1136/thoraxjnl-2012-203079

Kriemler, S., Keller, H., Saigal, S., and Bar-Or, O. (2005). Aerobic and lung performance in premature children with and without chronic lung disease of prematurity. Clin. J. Sport Med. 15, 349-355. doi: 10.1097/01.jsm.0000180023.44889.dd

MacLean, J. E., DeHaan, K., Fuhr, D., Hariharan, S., Kamstra, B., Hendson, L., et al. (2016). Altered breathing mechanics and ventilatory response during exercise in children born extremely preterm. Thorax 71, 1012-1019. doi: 10.1136/thoraxjnl-2015-207736

Markestad, T., Kaaresen, P. I., Ronnestad, A., Reigstad, H., Lossius, K., Medbo, S., et al. (2005). Early death, morbidity, and need of treatment among extremely premature infants. Pediatrics 115, 1289-1298. doi: 10.1542/peds.2004-1482

Narayanan, M., Beardsmore, C. S., Owers-Bradley, J., Dogaru, C. M., Mada, M., Ball, I., et al. (2013). Catch-up alveolarization in ex-preterm children: evidence from (3)He magnetic resonance. Am. J. Respir. Crit. Care Med. 187, 1104-1109. doi: $10.1164 / \mathrm{rccm} .201210-1850 \mathrm{OC}$

Santuz, P., Baraldi, E., Zaramella, P., Filippone, M., and Zacchello, F. (1995). Factors limiting exercise performance in long-term survivors of bronchopulmonary dysplasia. American journal of respiratory and critical care medicine. 152(4 Pt. 1), 1284-1289. doi: 10.1164/ajrccm.152.4.7551383

Satrell, E., Roksund, O., Thorsen, E., and Halvorsen, T. (2013). Pulmonary gas transfer in children and adolescents born extremely preterm. Eur. Respir. J. 42, 1536-1544, doi: 10.1183/09031936.00027112

Schwaiblmair, M., Faul, C., von Scheidt, W., and Berghaus, T. M. (2012). Ventilatory efficiency testing as prognostic value in patients with pulmonary hypertension. BMC Pulm. Med. 12:23. doi: 10.1186/1471-2466-12-23 
Simpson, S. J., Logie, K. M., O’Dea, C. A., Banton, G. L., Murray, C., Wilson, A. C., et al. (2017). Altered lung structure and function in mid-childhood survivors of very preterm birth. Thorax. doi: 10.1136/thoraxjnl-2016-208985. [Epub ahead of print].

Smith, L. J., van Asperen, P. P., McKay, K. O., Selvadurai, H., and Fitzgerald, D. A. (2008). Reduced exercise capacity in children born very preterm. Pediatrics 122, e287-e293. doi: 10.1542/peds.2007-3657

Vollsaeter, M., Skromme, K., Satrell, E., Clemm, H., Roksund, O., Oymar, K., et al. (2015). Children born preterm at the turn of the millennium had better lung function than children born similarly preterm in the early 1990s. PLoS ONE 10:e0144243. doi: 10.1371/journal.pone.0144243

Weibel, E. R. (2008). How to make an alveolus. Eur. Respir. J. 31, 483-485. doi: $10.1183 / 09031936.00003308$

Welsh, L., Kirkby, J., Lum, S., Odendaal, D., Marlow, N., Derrick, G., et al. (2010), The EPICure study: maximal exercise and physical activity in school children born extremely preterm. Thorax 65, 165-172. doi: 10.1136/thx.2008.107474
Wong, P. M., Lees, A. N., Louw, J., Lee, F. Y., French, N., Gain, K., et al. (2008). Emphysema in young adult survivors of moderateto-severe bronchopulmonary dysplasia. Eur. Respir. J. 32, 321-328. doi: 10.1183/09031936.00127107

Conflict of Interest Statement: The authors declare that the research was conducted in the absence of any commercial or financial relationships that could be construed as a potential conflict of interest.

Copyright (c) 2017 Hestnes, Hoel, Risa, Romstøl, Røksund, Frisk, Thorsen, Halvorsen and Clemm. This is an open-access article distributed under the terms of the Creative Commons Attribution License (CC BY). The use, distribution or reproduction in other forums is permitted, provided the original author(s) or licensor are credited and that the original publication in this journal is cited, in accordance with accepted academic practice. No use, distribution or reproduction is permitted which does not comply with these terms. 